\section{BENEFÍCIOS DO ALOJAMENTO CANGURU PARA MÃES DE PREMATUROS}

\section{KANGAROO HOSTING BENEFITS FOR PREMATURE MOTHERS}

Daiane de Carvalho Souza ${ }^{1}$ / Ivanete Fernandes do Prado ${ }^{1}$ / Midiã Ferreira do Santos ${ }^{1} /$ Mônica Aparecida de Jesus ${ }^{1, *} /$ Mônica da Silveira Matos ${ }^{1} /$ Romiria Brito dos Santos ${ }^{1}$

\section{INTRODUÇÃO}

A prematuridade é compreendida como o nascimento de um feto antes do tempo normal de gestação, que pode ser consequência de diversos fatores e na maioria das vezes ocorre de forma imprevisível. O tempo médio previsto de uma gravidez é de 268 dias (38 semanas e dois dias), contadas a partir do primeiro dia do último período menstrual. $\mathrm{O}$ nascimento de um prematuro pode ocorrer em diversos lugares, classes sociais e afeta diretamente a família do bebê e principalmente os pais, devido a expectativas que acompanha o nascimento de uma criança (Souza 2019).

A cada 10 nascimentos 1 é prematuro, somando 15 milhões de bebês segundo a Organização Mundial de Saúde (OMS), todo o ano. Os países em desenvolvimento são os que contêm a maior taxa de crianças que nascem de baixo peso, com cerca de 95,6\%. Entre os países em desenvolvimento está o Brasil, que ocupa o decimo lugar e o maior número total de nascimento de prematuros, com prevalência de $11,7 \%$. O sistema de informação sobre Nascidos Vivos (SINASC), traz dados oficiais entre os anos de 2000 a 2010, que indicam um discreto aumento da prevalência de nascidos prematuros no pais (Oliveira, 2019).

O Brasil tem criado mecanismos e traçado políticas de atenção e cuidados com essas crianças prematuras, evidenciada pela criação do método canguru criado no ano 2000 pelo Ministério da Saúde, no intuito de aumentar o vínculo da mãe com seu filho prematuro, através de ações como o contato pele a pele precoce promovendo também a interação dos pais no cuidado com os recém-nascidos (Oliveira, 2019).

\section{RESUMO}

Objetivo: Este trabalho tem como objetivo relatar a experiência de acadêmicas e docente do projeto de extensão e pesquisa intitulado "atividades lúdicas e educativas para mães de prematuros" referente à observação dos benefícios do alojamento canguru para mães de prematuros. Materiais e Métodos: Trata-se de um relato de experiência sobre a intervenção realizada pelas acadêmicas e docente do curso de enfermagem da Universidade do Estado da Bahia Campus XII, realizada no alojamento mãe canguru de um hospital público localizado na região sudoeste da Bahia, com as mães de recém-nascidos prematuros que ficam alojadas no hospital para acompanhar seus filhos que estão internados na unidade neonatal. Resultados: A permanência das mães no alojamento modificou o significado de ser acompanhante, pois favoreceram novas amizades, solidariedade, aconselhamentos e troca de experiências, minimizando os efeitos indesejáveis da hospitalização. Conclusão: Notou-se que o alojamento canguru proporciona as mães o acolhimento e o suporte que precisam para superar as dificuldades e desafios que é ser mãe de um bebê prematuro.

Palavras-chave: Saúde da criança. Alojamento. Prematuro.

\section{ABSTRACT}

Goal: This work aims to report the experience of academics and professor of the extension and research project entitled "Playful and educational activities for mothers of premature babies" regarding the observation of the benefits of kangaroo accommodation for mothers of premature babies. Materials and methods: This is an experience report about and professor of the nursing course at the State University of Bahia- Campus XII, held in the kangaroo mother's quarters of a public hospital located in the southwestern region of Bahia, with mothers of premature newborns who stay at the hospital to accompany their children who stay at the hospital to accompany their children who are hospitalized in the neonatal unit. Results: The stay of mothers in housing changed the meaning of being a companion, because they favored new friendships, solidarity, advice and exchange of experiences, minimizing the undesirable effects of hospitalization. Conclusion: It was noted that the kangaroo housing provides mothers the welcome and support they need to overcome difficulties and challenges which is to be the mother of a premature baby.

Keywords: Child health. Accommodation. Premature.

Submetido em: 08 de nov. 2019

Aceito em: 14 de fev. 2020

${ }^{1}$ Universidade do Estado da Bahia - UNEB, Guanambi, Bahia - Brasil.

*E-mail para correspondência: monica.ap-@hotmail.com

Rev. ComCiência - jun. 2020, vol. 5, no. 6, p. 70-73 / doi: 10.36112/ issn2595-1890.v5.i6.p70-73 
$\mathrm{O}$ alojamento canguru tem como finalidade aproximar mães de seus bebês e favorecer a interação e a participação ativa dos pais nos cuidados ao recém-nascido, através de orientações feita pelos profissionais para os tornarem aptos a prestar cuidados ao filho. Além de permitir a proximidade com a criança, melhora o humor, reduz o estresse, a ansiedade e a fadiga. Essas são as sensações vivenciadas pela mãe durante a internação do recém-nascido na Unidade de Terapia Intensiva Neonatal (UTIN) e na Unidade de Cuidados Intermediários Neonatal (UCIN), onde ocorre a separação precoce entre mãe e bebê (Sousa 2019).

Os bebês que permanece na UTIN são estereotipados pela prematuridade, pois passam a ser vistos como pouco maduros, fisicamente menos potentes, menos sociáveis e com menos capacidades cognitivas e isso pode influenciar negativamente a percepção materna. Pesquisas revelam que mães de recém-nascidos prematuros (RNPT) apresentam uma maior fragilidade psíquica, pelo fato de não ter vivenciado todo período da gestação e ter sua maternidade antecipada (Bortolin 2019).

Diante de tais problemáticas supracitadas, justifica-se a importância em compreender o processo que envolve os inúmeros benefícios do alojamento canguru para as mães de recém- nascidos prematuros, tornando o período de internação mais prazeroso e menos estressante.

Desta forma esse trabalho tem como objetivo relatar a experiência de acadêmicas e docente no projeto de extensão e pesquisa intitulado "atividades lúdicas e educativas para mães de prematuros" referente à observação dos benefícios do alojamento canguru para mães de recém-nascidos prematuros.

\section{MATERIAIS E MÉTODO}

\section{RESULTADOS E DISCUSSÃO}

Trata-se de um relato de experiência relacionada à intervenção realizada pelas acadêmicas monitoras e docente do curso de enfermagem da Universidade do Estado da Bahia Campus XII que atuam junto ao projeto de extensão e pesquisa intitulado "atividades lúdicas e educativas para mães de prematuros". Com a finalidade de preparar as monitoras para realização das intervenções do projeto, as mesmas foram previamente orientadas, com leituras de artigos e materiais sobre o tema, na instituição de ensino, juntamente com a docente coordenadora do projeto.

O primeiro passo da intervenção no alojamento canguru de um hospital público localizado na região sudoeste da Bahia, foi a apresentação da equipe do projeto, onde as acadêmicas se apresentaram para as mães de recémnascidos prematuros e explicaram o objetivo do projeto para as mesmas, em seguida foi solicitado pelas monitoras para as mães se apresentarem.

Passado as apresentações, foi observado pelas acadêmicas o funcionamento do alojamento mãe canguru e realizado uma conversa com as mães sobre o convívio delas, sobre o parto, idade gestacional, onde residiam, entre outros. As mães relataram sobre a experiência de estarem ali e o quanto tem sido importante a companhia e o apoio uma das outras, poderem trocar experiências, pois todas passam por situações parecidas.

Por se tratar de um relato de experiência não foi necessária a submissão ao Comitê de Ética em Pesquisa, mas foram tomados todos os cuidados referentes a um trabalho com seres humanos.
A partir da intervenção notou-se que o alojamento canguru além de fortalecer o vínculo dos pais com o bebê, proporciona a criação de laços entre as mães, o que diminui a ansiedade, o estresse e ajuda as mesmas a enfrentarem a prematuridade.

As mesmas relataram que elas formaram uma família, e que conviver com outras mães que enfrentam a mesma situação favorece a construção de relação de ajuda, elas confortam-se mutuamente e, mesmo diante de acontecimentos inesperados e desagradáveis, procuram unir forças, esperança e fé para vencer as dificuldades. As mães ainda relatam que a alta do bebê de uma é comemorada por todas, e mesmos depois de saírem do hospital ainda continuam tendo contato, através de grupo de redes sociais.

A permanência das mães no alojamento materno modificou o significado de ser acompanhante, pois favoreceram novas amizades, solidariedade, aconselhamentos e troca de experiências, minimizando os efeitos indesejáveis da hospitalização. A família também é uma importante fonte de apoio para as mães durante sua permanência no alojamento materno, pois essas se mostram presentes nos momentos difíceis e buscam atender às suas necessidades (UNIT, 2008).

Durante a gravidez a maioria das mães idealizam o bebê perfeito, saudável e forte, por isso, ao se depararem com o bebê prematuro, sentem medo, insegurança e rejeição por aquele ser tão pequeno e frágil, tão diferente daquele desejado. Lamentam a perda do bebê perfeito que imaginavam, sentimento de culpa e impotência. Neste pensar, faz-se necessário o apoio da equipe de enfermagem no sentido de facilitar o processo de ade- 
quação da imagem do bebê imaginário com a imagem do bebê real, facilitando, assim, o processo de luto do bebê imaginário e enfrentamento das diferenças do bebê real (ARAUJO et al, 2010).

O apoio que a mãe recebe, inclusive dos profissionais, são fundamentais para que ela possa desempenhar o seu papel de acompanhante. A participação das mães nas atividades de lazer e em outros atendimentos grupais realizados pela equipe multiprofissional possibilita que elas se distanciem da difícil situação que estão vivendo e compartilhem momentos de alegria e descontração (CAETANO, 2004).

Algumas mães permanecem por tempo prolongado no ambiente hospitalar, expostas a situação de risco contínuo dos filhos, são impedidas de cuidarem de si própria e atender às suas necessidades como alimentação, repouso e sono, manifestando sinais evidentes de cansaço físico e mental. Sendo conhecedoras da dimensão do sofrimento que as envolvem, encontra umas nas outras o suporte que necessitam, motivadas pelas necessidades e experiências em comum, procuram compartilhar alegrias e tristezas, seguindo juntas no alojamento materno, convivem e buscam superar as dificuldades que passam, pois sabem que o desejo de recuperação do filho supera qualquer desafio (UNIT, 2008).

A decisão de permanecer no alojamento canguru durante a hospitalização do filho prematuro não é algo fácil, a mãe é forçada a romper com sua cotidianidade e a se afastar dos demais membros da família. Ao priorizarem a presença junto ao filho hospitalizado, para as mães que possuem outros filhos, ressentem-se de não poder dar assistência aos outros que ficaram em casa. Os conflitos que emergem da nova situação, exigem delas conviver com as demandas do companheiro, dos outros filhos, dos familiares e dela própria, além de se depararem com o anseio de voltarem para casa e retornar a rotina e o cotidiano que viviam antes do nascimento do filho (VASCONCELOS et al, 2006).

A capacidade da mãe em aceitar sua condição de acompanhante e a nova realidade a ponto de interromper temporariamente sua rotina e se dedicar integralmente ao recém-nascido prematuro decorre do desejo de contribuir para a sobrevivência do filho, cumprindo assim seu papel de mãe, de proteger e cuidar do seu bebê. Essa presença constante representa a ligação de amor construída durante a gestação, o que não lhes permitem deixar o hospital sem levar seus filhos nos braços (ALMEIDA et al, 2018)

\section{CONCLUSÃO}

Conclui se então, que o alojamento canguru proporciona as mães o acolhimento e o suporte que precisam para superar as dificuldades e desafios que é ser mãe de um bebê prematuro, por meio da criação de laços de amizades e de afeto, da troca experiências, do compartilhamento de alegrias, oferecendo o ombro amigo e sabendo que possuem umas às outras.

Os benefícios do alojamento canguru vão além do fortalecimento de vinculo dos pais com os seus bebês, ele auxilia na redução do estresse e da ansiedade, permite que as mães se sintam atuantes nos cuidados dos seus bebês e as capacita para o cuidado domiciliar.

A experiência de conviverem no alojamento canguru é enriquecedora, pois possibilita que essas mães possam ajudar futuramente outras mães que venham a passar pala mesma situação e servirem até mesmo de exemplo de superação e incentivos para outras mães de recém-nascidos prematuro.

\section{REFERÊNCIAS}

ALMEIDA, Cinthia Reis et al. Cotidiano de mães acompanhantes na Unidade de Terapia Intensiva Neonatal. Rev. enferm. UFPE on line, v. 12, n. 7, p. 1949-1956, 2018.

ARAÚJO, Bárbara Bertolossi Marta; RODRIGUES, Benedita Maria Rêgo Deus Dará. O alojamento de mães de recém-nascidos prematuros: uma contribuição para a ação da enfermagem. Escola Anna Nery Revista de Enfermagem, v. 14, n. 2, p. 284-292, 2010.

BORTOLIN, Denice; DONELLI, Tagma Marina Schneider; TABACZINSKI, Carine. Experiências maternas no contexto da prematuridade: Um estudo de revisão sistemática. PSI UNISC, v. 3, n. 2, p. 142-155, 2019. CAETANO LC. Vivendo no método canguru: a tríade mãe filho-família [tese doutorado]. Ribeirão Preto: Escola de Enfermagem da Universidade de São Paulo; 2004.

OLIVEIRA, Janaína Aparecida et al. Continuidade do cuidado na prematuridade. Saúde (Santa Maria), v. 45, n. 1, 2019.

SOUSA Silvelene Carneiro et al. "fortalecimento do vínculo entre a família e o neonato prematuro." Journal of Nursing UFPE/Revista de Enfermagem UFPE 13.2 2019.

SOUZA, Daniel Miranda Lopes et al. Prevalência de prematuridade e fatores associados no estado do Rio Grande do Sul/Prevalence of prematurity and associated factors in the state of Rio Grande do Sul. Brazilian Journal of Health Review, v. 2, n. 5, p. 40524070, 2019.

UNIT, Care. O cotidiano no alojamento materno, das mães de crianças in- 
ternadas em uma Unidade de Terapia Intensiva Neonatal. Rev. Bras. Saúde Matern. Infant., Recife, 8 (1): 75-81, jan. / mar., 2008.

VASCONCELOS MGL, Leite AM, Scochi CGS. Significados atribuídos à vivência materna como acompanhante do recém-nascido pré-termo e de baixo peso. Rev Bras Saúde Matern In-

fant. $2006 ; 6: 47-57$. 